\title{
N-ТРОПИЛИРОВАНИЕ АРИЛАМИНОВ
}

\author{
Л.П. Юнникова, Ю.Е. Лихарева, С.Ю. Баландина
}

Лидия Петровна Юнникова *, Юлия Евгеньевна Лихарева

Кафедра общей химии, Пермский государственный аграрно-технологический университет им. академика Д.Н. Прянишникова, ул. Петропавловская, 23, Пермь, Пермский край, Российская Федерация, 614990

E-mail: yunnikova@yahoo.com*,ullix@yandex.ru

Светлана Юрьевна Баландина

Лаборатория «Бактерицид», Химический факультет, Пермский государственный научно-исследовательский университет, ул. Букирева, 15, Пермь, Пермский край, Российская Федерация, 614990

E-mail: bactericid@yandex.ru

Предложен эффективный метод введения биогенного тропилиевого цикла в молекуль ароматических аминов, осуществляемый в присутствии сильного основания - имидазола. Взаимодействием солей тропилия (тетрафторбората или перхлората) с аминами ароматического ряда, имеющими в бензольном кольце электроноакцепторные заместители нитро- или ацетильную группь (мета-нитроанилин, пара-нитроанилин, 2-метил-4-нитроанилин и пара-ацетиланилин) получены устойчивые продукты замещения атома водорода в аминогруппе ароматического амина, а именно: 4-нитро-N-(1'-циклогепта-2',4',6'-триенил)анилин, 2-метил-4-нитро- $N$-(1'-циклогепта-2',4',6'-триенил)анилин, 3-нитро- $N$-(1'-циклогепта-2',4',6'-триенил)анилин, 4-ацетил- $N$-(1'-циклогепта-2',4',6'-триенил)анилин. Выходы полученных соединений достигают 60-87\%. Роль имидазола в данном процессе заключается в том, что он связывается с катионом тропилия в комплекс, который: 1) служит переносчиком тропилиевого иона к атому азота ароматического амина, в результате чего облегчается процесс электрофильного замещения у атома водорода аминогруппы; 2) препятствует протеканию процесса дегидрирования получающихся $N$-(1'-циклогепта-2',4',6'-триенил)анилинов, что является преимуществом по сравнению с методом, в котором в результате дегидрирования вместо $N$-тропилированных анилинов образуются неустойчивые $N$ арил-8-азагептафульвены. Строение полученных соединений подтверждено методами массспектрометрии, ядерно-магнитного резонанса на ядрах протия и методом рентгеноструктурного анализа для соединения 4-нитро- $N$-(1'-циклогепта-2',4',6'-триенил)анилина. Антимикробная активность изучена на музейных условно-патогенных штаммах микроорганизмов: St. aureus 906, C. albicans ATCC 24433 и E. coli 1257. Результаты исследований показали, что все синтезированные соединения обладают антимикробной активностью. Установлено, что соединения $\mathrm{N}$-(3-нитрофенил)циклогепта-2,4,6-триенамин и $\mathrm{N}$-(4-ацилфенил)циклогепта-2,4,6-триенамин проявили ингибирующее действие на рост и развитие тестерных штаммов в концентрации 125 мкг/мл, для соединений $N$-(4-нитрофенил)циклогепта-2,4,6триенамин и $\mathrm{N}$-(2-метил-4-нитрофенил)циклогепта-2,4,6-триенамин ингибирующее действие в отночении этих же штаммов менее выражено.

Ключевые слова: мета-нитроанилин, пара-нитроанилин, 2-метил-4-нитроанилин, пара-аминоацетофенон, тетрафторборат или перхлорат тропилия 


\section{N-TROPYLATION OF ARYLAMINES}

\section{L.P. Yunnikova, Yu.E. Likhareva, S.Yu. Balandina}

Lidiya P. Yunnikova *, Yuliya E. Likhareva

Department of General Chemistry, Perm State Agro-Technological University, Petropavlovskaya st., 23, Perm, 614990, Russia

E-mail: ullix@yandex.ru, yunnikova@yahoo.com*

Svetlana Yu. Balandina

Laboratory "Bactericide", Faculty of Chemistry, Perm State University, Bukireva st., 15, Perm, 614990, Russia E-mail: bactericid@yandex.ru

An efficient method for introduction of biogenic tropylium cycle into aromatic amines molecules is offered. Introduction is carried out in the presence of imidazole as a strong base. Interaction between tropylium salts (tetrafluoroborate or perchlorate) and aromatic amines with either nitro- or acetyl groups (meta-nitroaniline, para-nitroaniline, 2-methyl-4-nitroaniline and paraacetylaniline) as electron-acceptor substituents in the benzol ring results in stable products resulting from substitution of the hydrogen atom in the amino group of aromatic amines, namely: 4nitro- $N$-(1'-cyclohepta-2',4',6'-trienil)aniline, 2-methyl-4-nitro- $N$-(1'-cyclohepta-2',4',6'-trienil)aniline, 3-nitro- $N$-(1'-cyclohepta-2',4',6'-trienil)aniline, 4-acetyl- $N$-(1'-cyclohepta-2',4',6'-trienil)aniline. The yields of the compounds obtained attain 60-87\%. In this process, imidazole forms with the tropylium cation a complex which (1) serves as a carrier of tropylium ion to the nitrogen atom of aromatic amine, thus lightening the electrophilic substitution process at the hydrogen atom of the amino group; (2) prevents the dehydration process of resulting $N$-(1'-cyclohepta-2',4',6'-trienil) anilines. The latter phenomenon is an advantage in comparison with the method in which the dehydration process results in unstable $N$-aryl-8-azaheptafulvenes instead of stable $N$-tropylated anilines. The structure of the compounds obtained is confirmed by the method of mass spectrometry, NMR on protium nuclei and XRD analysis for 4-nitro- $N$-(1'-cyclohepta-2',4',6'-trienil)aniline. Antimicrobial activity is studied on conditionally pathogenic St. aureus 906, C. albicans ATCC 24433 and $E$. coli 1257 strains. The investigation results show all the synthesized compounds to exhibit antimicrobial activity. The compounds $\mathrm{N}$-(3-nitrophenyl)cyclohepta-2,4,6-trienamine and $\mathrm{N}$-(4acylphenyl)cyclohepta-2,4,6-trienamine at concentration 125 microgram/ml are ascertained to exhibit inhibitory action on growth and development of the test strains, with this effect being less expressed for compounds $N$-(4-nitrophenyl)cyclohepta-2,4,6-trienamine and N-(2-methyl-4-nitrophenyl)cyclohepta-2,4,6-trienamine.

Key words: $p$-aminoacetophenone, $m$-, $p$-nitroanilines, 2-methyl-4-nitroaniline, tetrafluoroborate or perchlorate of tropylium, imidazole

Для цитирования:

Юнникова Л. П., Лихарева Ю.Е., Баландина С.Ю. N-Тропилирование ариламинов. Изв. вузов. Химия и хим. технология. 2019. Т. 62. Вып. 2. С. 79-84

For citation:

Yunnikova L.P., Likhareva Yu.E., Balandina S.Yu. N-Tropylation of arylamines. Izv. Vyssh. Uchebn. Zaved. Khim. Khim. Tekhnol. 2019. V. 62. N 2. P. 79-84

Органическим соединениям, содержащим в своем составе 1,3,5-циклогептатриеновый (тропилиевый) фрагмент, посвящено значительное количество исследований, что отчасти связано с их высокой биологической активностью [1-12]. Производные 1,3,5-циклогептатриена используют для получения новых соединений в реакциях [8+2]циклоприсоединения [13].
Известно [14], что взаимодействие тетрафторбората тропилия с ариламинами приводит к неустойчивым $\mathrm{N}$-продуктам - $\mathrm{N}$-(1'-циклогепта$2^{\prime}, 4^{\prime}, 6^{\prime}$-триенил)анилинам, которые легко дегидрируются в процессе реакции с образованием более устойчивых $\mathrm{N}$-арил-8-азагептафульвенов. Недавно [15] нами была показана возможность взаимодей- 
ствия 2-аминопиридина с хлоридом тропилия с образованием устойчивого $\mathrm{N}$-(1'-циклогепта- $2^{\prime}, 4^{\prime}, 6^{\prime}$ триенил)2-аминопиридина, обладающего умеренным антимикробным действием в отношении Staphylococcus aureus 906 и Candida albicans ATCC 24433.

Цель данного исследования - изучить возможность образования продуктов электрофильного замещения у атома азота ароматических аминов с участием солей тропилия, выяснить их устойчивость и антимикробную активность.

Нами установлено, что ариламины, содержащие электроноакцепторные группы в пара- или мета-положениях, при взаимодействии с тетрафторборатом или перхлоратом тропилия в присутствии имидазола образуют устойчивые N-продукты - замещенные N-(1'-циклогепта-2', $4^{\prime}, 6^{\prime}$-три- енил)анилины 3a-d (схема), которые не подвергаются гидролизу и не склонны к процессам дегидрирования и сужения циклогептариенового цикла, как было отмечено ранее [16]. Сильное основание имидазол, связываясь с катионом тропилия в комплекс, в данной реакции выполняет роль переносчика катиона тропилия к атому азота ароматического амина, что способствует повышению выхода конечных продуктов. Кроме того, комплекс препятствует дегидрированию образующихся $\mathrm{N}-\left(1^{\prime}-\right.$ циклогепта-2',4',6'-триенил)анилинов, так как концентрация свободного катиона тропилия снижена. Следует отметить, что такой ароматический амин, как 2,4-динитроанилин в данной реакции остался без изменения, что можно объяснить пространственными трудностями из-за наличия в орто-положении объемной нитро-группы.

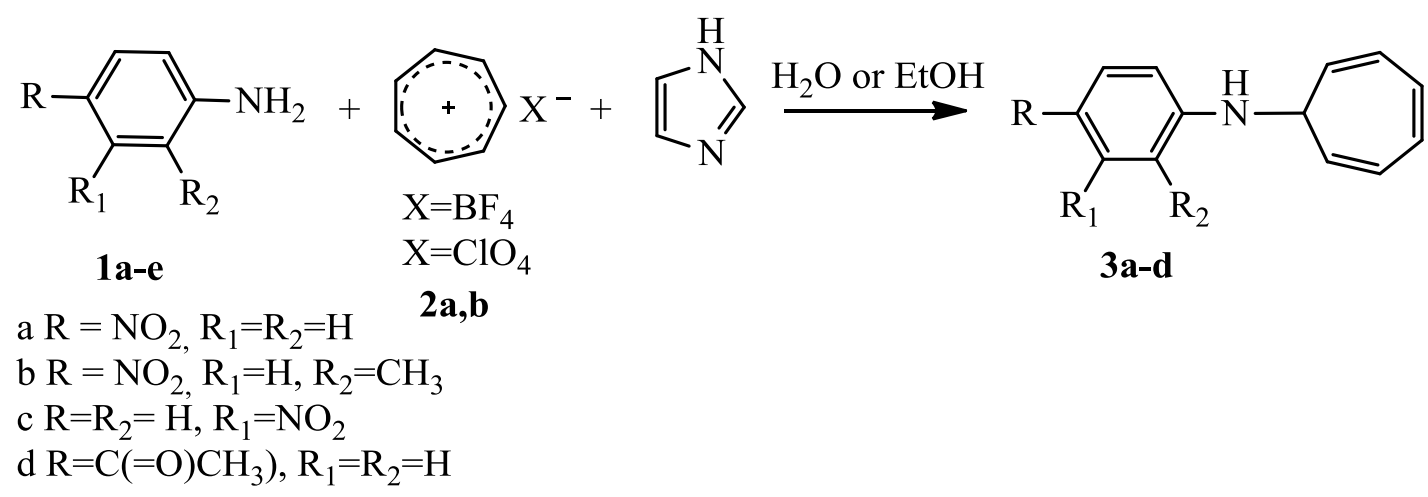

Структура полученных соединений доказана с помощью ЯМР ${ }^{1} \mathrm{H}$ спектроскопии, масс-спектрометрии и рентгеноструктурного анализа (для соединения 3a).

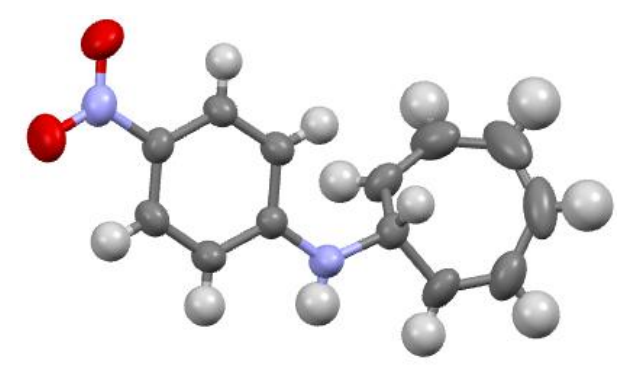

Рис. 1. Общий вид молекулы (3a) в тепловых эллипсоидах $50 \%$ вероятности

Fig. 1. General view of the molecule (3a) in thermal ellipsoids of $50 \%$ probability

\section{ЭКСПЕРИМЕНТАЛЬНАЯ ФАРМАКОЛОГИЧЕСКАЯ ЧАСТЬ}

Антимикробную активность изучали на музейных условно-патогенных штаммах микроорга- низмов: Staphylococcus aureus 906, Candida albicans ATCC 24433 и Escherichia coli 1257. Для исследований использовали общепринятый метод двукратных серийных разведений [17]. Готовили исходные разведения микроорганизмов в физиологическом растворе из суточной агаровой культуры по оптическому стандарту мутности (ОСО) на 5 ME. Микробная нагрузка соответствовала $2,5 \cdot 10^{5}$ микробных тел в 1 мл. Микробную взвесь вносили в изготовленные разведения препаратов в жидкой питательной среде. Предварительно все соединения растворяли в 0,5 мл ДМСО. Факт ингибирования (торможения) роста микроорганизмов отмечали визуально после 20 ч культивирования при $37 \pm 1{ }^{\circ} \mathrm{C}$. Окончательные результаты фиксировали через 7 сут. Противомикробную (ингибирующую и бактерицидную) активность оценивали по минимальной действующей концентрации.

Результаты исследования приведены в таблице в сравнении с активностью препарата - фенилсалицилата. 
Результаты исследования противомикробных свойств соединений

Table. Results of the study of the antimicrobial properties of compounds

\begin{tabular}{|c|c|c|c|c|c|c|}
\hline \multirow{2}{*}{ Шифр соединения } & \multicolumn{4}{|c|}{ Противомикробная активность, мкг/мл } \\
\cline { 2 - 7 } & \multicolumn{2}{|c|}{ St. aureus } & \multicolumn{2}{c|}{ E. coli } & \multicolumn{2}{c|}{ C. albicans } \\
\cline { 2 - 7 } & ${ }^{*}$ МИК & ${ }^{* *}$ МБК & МИК & МБК & МИК & МБК \\
\hline 3a & 500,0 & 1000,0 & 500,0 & 1000,0 & 500,0 & 1000,0 \\
\hline 3b & 250,0 & - & 500,0 & 1000,0 & 250,0 & 250,0 \\
\hline 3c & 125,0 & 250,0 & 250,0 & 250,0 & 125,0 & 250,0 \\
\hline 3d & 125,0 & 250,0 & 250,0 & 250,0 & 125,0 & 500,0 \\
\hline Фенилсалицилат & 750,0 & 2000,0 & - & - & - & - \\
\hline Контроль среды & Рост & Рост & Рост & Рост & Рост & Рост \\
\hline
\end{tabular}

Примечание: (-) - отсутствие противомикробного действия в испытанных концентрациях; *МИК - минимальная ингибирующая концентрация; **МБК - минимальная бактерицидная концентрация

Note: (-) - no antimicrobial effect in tested concentrations; * MIC is the minimum inhibitory concentration; ** MBC is the minimum bactericidal concentration

\section{ЭКСПЕРИМЕНТАЛЬНАЯ ЧАСТЬ}

Спектры ЯМР ${ }^{1} \mathrm{H}$ зарегистрированы на приборе Mercury 300 (300МГц), внутренний стандарт ГМДС. Масс-спектры получены на квадрупольновремяпролетном масс-спектрометре сверхвысокого разрешения maXis Impact HD Daltonik $\mathrm{GmbH}$ в режиме регистрации положительных ионов в условиях химической ионизации при атмосферном давлении (APCI).

\section{4-Нитро- $\boldsymbol{N}$-(1'-циклогепта-2', $\mathbf{4}^{\prime}, \mathbf{6}^{\prime}$-трие-}

нил)анилин За. К 0,19 г перхлората или 0,18 г тетрафторбората тропилия (1 ммоль) и 0,07 г имидазола (1 ммоль) в 7 мл дистиллированной воды (или этанола) добавляют 0,21 г 4-нитроанилина (1,5 ммоль) при комнатной температуре и перемешивании. Через 3 ч нейтрализуют $10 \% \mathrm{NH}_{4} \mathrm{OH}$ до $\mathrm{pH} 7$, оставляют до кристаллизации. Выход 0,20 г (87\%). Оранжевые иглы с Т.пл. 143-144 ${ }^{\circ} \mathrm{C}$. ЯМР ${ }^{1} \mathrm{H}$ спектр $\left(\mathrm{CDCl}_{3}\right), \delta$, м.д.: 3,65 (д.т, $1 \mathrm{H}, \mathrm{J}_{1,2}=4,5$ Гц, $\mathrm{J}_{2,3}=5,4$ Гц, $\mathrm{C}^{1} \mathrm{H}_{\text {в }} \mathrm{C}_{7} \mathrm{H}_{7}$ ), 4,90 (уш. с, $1 \mathrm{H}, \mathrm{NH}$ ), 5,45$5,48\left(\mathrm{M}, 2 \mathrm{H}, \mathrm{C}^{2^{\prime}, 7^{\prime}} \mathrm{H}\right.$ в $\left.\mathrm{C}_{7} \mathrm{H}_{7}\right), 6,31-6,35$ (м, 2H, $\mathrm{C}^{3^{\prime}, 6^{\prime}} \mathrm{H}$ в $\mathrm{C}_{7} \mathrm{H}_{7}$ ), 6,55-6,59 (м, 2H, C ${ }^{\prime}, 5^{\prime} \mathrm{H}$ в $\mathrm{C}_{7} \mathrm{H}_{7}$ ), 6,77-6,83 (м, 2H, Ar), 8,07-8,11 (м, 2H, Ar). Найдено: 251,0791 $[\mathrm{M}+\mathrm{Na}]^{+} . \quad \mathrm{C}_{13} \mathrm{H}_{12} \mathrm{~N}_{2} \mathrm{NaO}_{2}$. Вычислено: 251,0956 $\left[\mathrm{C}_{13} \mathrm{H}_{12} \mathrm{~N}_{2} \mathrm{NaO}_{2}\right]^{+}$.

Аналогичной методикой получены соединения 3b-d.

2-Метил-4-нитро-N-(1'-циклогепта-2',4',6'триенил)анилин 3b. Выход 0,15 г (61\%). Желтые кристаллы с Т.пл. 117-118 ${ }^{\circ} \mathrm{C} .{ }^{1} \mathrm{H}$ ЯМР спектр $\left(\mathrm{CDCl}_{3}\right), \delta$, м.д.: 2,19 (c, 3H, $\left.\mathrm{CH}_{3}\right), 3,68$ (д.т, $1 \mathrm{H}, \mathrm{J}_{1,2}$ $=4,5 \Gamma ц, \mathrm{~J}_{2,3}=5,4$ Гц, $\mathrm{C}^{1} \mathrm{H}_{\text {в }} \mathrm{C}_{7} \mathrm{H}_{7}$ ), 4,54 (уш.с, $1 \mathrm{H}$,

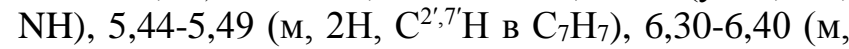

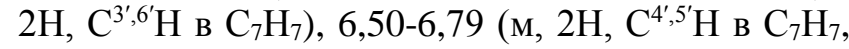
$1 \mathrm{H}$ в $\mathrm{Ar}), 7,97-8,01$ (м, 2H, J = 9,0 Гц, Ar). Найдено: $265,1112[\mathrm{M}+\mathrm{Na}]^{+} . \mathrm{C}_{14} \mathrm{H}_{14} \mathrm{~N}_{2} \mathrm{NaO}_{2}$. Вычислено: $265,1112\left[\mathrm{C}_{14} \mathrm{H}_{14} \mathrm{~N}_{2} \mathrm{NaO}_{2}\right]^{+}$.

\section{3-Нитро-N-(1'-циклогепта-2', 4',6' -трие-} нил)анилин 3с. Выход 0,15 г (66\%). Оранжевожелтые кристаллы с Т.пл. $74{ }^{\circ} \mathrm{C}$. Спектр ${ }^{1} \mathrm{H}$ ЯМР

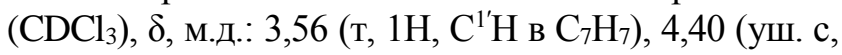

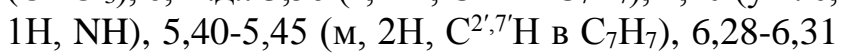
(м, 2H, C $3^{\prime}, 6^{\prime} \mathrm{H}$ в $\left.\mathrm{C}_{7} \mathrm{H}_{7}\right), 6,76-6,78$ (м, 2H, $\mathrm{C}^{4^{\prime}, 5^{\prime}} \mathrm{H}$ в $\mathrm{C}_{7} \mathrm{H}_{7}$ ), 7,10-7,55 (м, 3H, Ar), 7,89-7,91 (д, 1Н, J = 7,5 Гц, napa-Ar). Найдено: $251,0791[\mathrm{M}+\mathrm{Na}]^{+} . \mathrm{C}_{13} \mathrm{H}_{12} \mathrm{~N}_{2} \mathrm{NaO}_{2}$. Вычислено: 251,0956 [ $\left.\mathrm{C}_{13} \mathrm{H}_{12} \mathrm{~N}_{2} \mathrm{NaO}_{2}\right]^{+}$.

4-Ацетил-N-(1'-циклогепта-2',4',6' -триенил)анилин 3d. Выход 0,14 г (60,5\%). Светло-желтые кристаллы с Т.пл. $102-104^{\circ} \mathrm{C}$. Спектр ${ }^{1} \mathrm{H}$ ЯМР $\left(\mathrm{CDCl}_{3}\right)$, $\delta$, м.д.: 2,48 (c, 3H, $\left.\mathrm{CH}_{3}\right), 3,55$ (д.т, $1 \mathrm{H}, \mathrm{C}^{1} \mathrm{H}$ в $\mathrm{C}_{7} \mathrm{H}_{7}$ ), 4,64 (уш. с, 1H, NH), 5,40-5,44 (м, 2H, $\mathrm{C}^{2^{\prime}, 7^{\prime}} \mathrm{H}$ в $\left.\mathrm{C}_{7} \mathrm{H}_{7}\right), 6,25-6,28$ (м, 2H, $\mathrm{C}^{3^{\prime}, 6^{\prime}} \mathrm{H}$ в $\left.\mathrm{C}_{7} \mathrm{H}_{7}\right), 6,56-6,58$ (д, $2 \mathrm{H}, \mathrm{J}=8,7$ Гц, в $\mathrm{C}^{2,6} \mathrm{H}$ в $\mathrm{Ar}$ ), 6,76 (т, 2H, J = 3,0 Гц, $\mathrm{C}^{4^{\prime}, 5^{\prime}} \mathrm{H}$ в $\mathrm{C}_{7} \mathrm{H}_{7}$ ), 7,78-7,81 (д, 2H, J = 9,0 Гц, $\mathrm{C}^{3,5} \mathrm{H}$ в Ar). Найдено: 248,1042 [M+Na] $]^{+} \mathrm{C}_{15} \mathrm{H}_{15} \mathrm{NNaO}$. Вычислено: 248, 1046. [ $\left.\mathrm{C}_{15} \mathrm{H}_{15} \mathrm{NNaO}\right]^{+}$.

Рентгеноструктурный анализ соединения 3а. Параметры элементарных ячеек и интенсивности отражений измерены на дифрактометре Xcalibur R. Поглощение учтено эмпирическим методом мульти-скан с использованием алгоритма SCALE3 ABSPACK [18]. Структуры расшифрованы прямым методом и уточнены полноматричным МНК с использованием программного пакета SHELX97 [19, 20].

Кристалл соединения 3a $\mathrm{C}_{13} \mathrm{H}_{12} \mathrm{~N}_{2} \mathrm{O}_{2}$ (M = $228,25)$ принадлежит к ромбической сингонии: $a$ 18,601(6), b 6,772(2), c 8,916(4) $\AA, V$ 1123,1(7) $\AA^{3}$, $Z 4$, пространственная группа $P$ са $2_{1}$. На углах рассеяния $3,008^{\circ}<\theta<29,398^{\circ}$ собрано 3562 отражения. В кристалле молекулы связаны в бесконечные цепочки посредством межмолекулярной водородной связи $\mathrm{N}^{1}-\mathrm{H}^{1} \cdots \mathrm{O}^{2}[1,5-\mathrm{x}, 1+\mathrm{y}, \mathrm{z}-0,5]$ с параметрами $[\mathrm{d}(\mathrm{D}-\mathrm{H})=0,83(6) \AA, \mathrm{d}(\mathrm{D} \cdots \mathrm{A})=3,257(6) \AA$, 
$\mathrm{d}\left(\mathrm{H}^{\cdots} \mathrm{A}\right)=2,45(62) \AA$, угол DHA $\left.164(5)^{\circ}\right]$. Окончательные параметры уточнения: $R_{1} 0,0500, w R_{2}$ $0,1004$ [для 1134 отражений с $I>2 \sigma(I)], R_{1} 0,1002$, $w R_{2} 0,1351$ (для всех 2113 независимых отражений), $S 0,992$.

\section{ВЫВОДЫ}

Установлено, что устойчивые продукты Nтропилирования замещенных анилинов образуются только с низкоосновными ароматическими

\section{ЛИТЕРА Т УРА}

1. Эсенбаева В.В., Юнникова Л.П. Амиды сульфаниловой, тио- и угольной кислот в реакции с солями тропилия. Журн. общ. химии. 2018. Т. 88. Вып. 4. С. 683-685.

2. Эсенбаева В.В., Смирнова А.И., Усольцева Н.В., Юнникова Л.П., Акентьева Т.А. Синтез и мезоморфизм Nфенилметилен-4-(7-циклогепта-1,3,5-триенил)анилинов. Жидк. кристаллы и их практ. использ. 2015. Т. 15. № 2. C. 26-34.

3. Юнникова Л.П., Акентьева Т.А., Александрова Г.А., Михайлова Л.А., Елисеев С.Л. Синтез и противомикробная активность анилинов с фрагментами 1,3,5-циклогептатриена и 5Н-дибензо[a,d]аннулена. Хим.-фарм. журн. 2014. Т. 48. № 1. С. 26-29.

4. Эсенбаева В.В., Акентьева Т.А., Юнникова Л.П., Дмитриев М.В. Строение 4-(7-циклогепта-1,3,5-триенил)анилина и синтез 4-(7-циклогепта-1,3,5-триенил)-N(1-циклогепта-2,4,6-триенил)анилина. Бутлеров. сообщ. 2014. T. 39. № 10. C. 51-53.

5. Горохов В.Ю., Юнникова Л.П. Гетерилирование и тропилирование N-бензил-4-(9Н-(тио)ксантен-9-ил)анилинов. Бутлеров. сообщ. 2014. T. 37. № 2. С. 159-162.

6. Yunnikova L.P., Akentieva T.A., Makhova T.V. One-pout three-component synthesis of N-arylmethyl-4-(7-cyclohepta1,3,5-trienil)anilines. I. J. Org. Chem. 2013. V. 3. N 2. P. 148-150.

7. Юнникова Л.П., Акентьева Т.А., Александрова Г.А. Синтез и противомикробная активность аминов и иминов с циклогептатриеновым фрагментом. Хим.-фарм. журн. 2012. Т. 46. № 12. С. 27-29.

8. Юнникова Л.П., Эсенбаева В.В., Шкляева Е.В. Соли тропилия и тритилия в реакциях С 2-амино-4,6-дизамещен-ными пиримидинами. Изв. вузов. Химия и хим. технология. 2018. Т. 61. Вып. 8. С. 47-52.

9. Акентьева Т.А., Юнникова Л.П., Махова Т.В., Александрова Г.А. 4-(7-циклогепта-1,3,5-триенил)анилин и производные с антимикобактериальной активностью. Бутлеров. сообщ. 2012. Т. 32. № 10. С. 22-26.

10. Акентьева Т.А., Юнникова Л.П. Синтез аминов с тропилиденовым фрагментом с потенциальной антифунгальной активностью. Бутлеров. сообщ. 2011. Т. 28. № 20. С. 80-83.

11. Юнникова Л.П., Акентьева Т.А. Синтез N-арилметил-4-(1циклогепта-2,4,6-триенил) анилинов. Естеств. и технич. науки. 2010. № 6 (50). С. 86-90.

12. Fehlinger M., Abraham W. Calix[4]arenes bearing a tropylium substituent as hosts for organic cations. J. Incl. Phenom. Macrocyclic Chem. 2007. V. 58. N 3-4. P. 263-274. аминами, имеющими в качестве заместителя в мета- или пара-положениях электроноакцепторные нитро-группу или пара-ацетильную группу.

Наибольший антимикробный эффект оказали соединения 3-нитро-N-(1'-циклогепта-2',4',6'триенил)анилина 3с и 4-ацетил-N-(1'-циклогепта2',4',6'-триенил)анилина 3d, которые при минимальной ингибирующей концентрации (125,0 мкг/мл) подавляют рост St. aureus и C. albicans.

\section{REFERENCES}

1. Esenbaeva V.V., Yunnikova L.P. Amides of sulfanyl, thio and carbonic acids in reaction with salts of tropylium. Zhurn. Obshch. Khim. 2018. V. 88. N 4. P. 683-685 (in Russian).

2. Esenbaeva V.V., Smirnova A.I., Usoltseva N.V., Yunnikova L.P., Akent'eva T.A. Synthesis and mesomorphism of N-phenylmethylene-4-(7-cyclohepta-1,3,5-trienyl) anilines. Zhidk. Kryst.their Prakt. Ispolz. 2015. V. 15. N 2. P. 26-34 (in Russian).

3. Yunnikova L.P., Akent'eva T.A., Alexandrova G.A., Mikhailova L.A., Eliseev S.L. Synthesis and antimicrobial activity of anilines with fragments of 1,3,5-cycloheptatriene and 5H-dibenzo [a, d] annulene. Khim.-Farm. Zhurn. 2014. V. 48. N 1. P. 26-29 (in Russian).

4. Esenbaeva V.V., Akent'eva T.A., Yunnikova L.P., Dmitriev M.V. The structure of 4- (7-cyclohepta-1,3,5-trienyl) aniline and the synthesis of 4- (7-cyclohepta-1,3,5-trienyl) -N- (1-cyclohepta-2,4,6-trienyl) aniline. Butlerov Commun. 2014. P. 39. N 10. P. 51-53.

5. Gorokhov V.Yu., Yunnikova L.P. Heterylation and trolling of N-Benzyl-4- (9H- (thio) xanthen-9-yl) anilines. Butlerov Soobshch. 2014. V. 37. N 2. P. 159-162 (in Russian).

6. Yunnikova L.P., Akentieva T.A., Makhova T.V. One-pout three-component synthesis of N-arylmethyl-4-(7-cyclohepta-1,3,5-trienil)anilines. I. J. Org. Chem. 2013. V. 3. N 2. P. 148-150.

7. Yunnikova L.P., Akent'eva T.A., Alexandrova G.A. Synthesis and antimicrobial activity of amines and imines with a cycloheptatriene moiety. Khim.-Farm. Zhurn. 2012. V. 46. N 12. P. 27-29 (in Russian).

8. Yunnikova, L.P., Esenbaeva V.V., Shklyaeva E.V. Tropylium and tritylium salts in reactions with 2-amino-4,6-disubstituted pyrimidines. Izv. Vyssh. Uchebn. Zaved. Khim. Tekhnol. 2018. V. 61. N 8. P. 47-52. DOI: 10.6060/ivkkt.20186108. 5817 (in Russian).

9. Akent'eva T.A., Yunnikova L.P., Makhova T.V., Alexandrova G.A. 4- (7-cyclohepta-1,3,5-trienyl) aniline and derivatives with antimycobacterial activity. Butlerov Soobshch. 2012. V. 32. N 10. P. 22-26 (in Russian).

10. Akent'eva T.A., Yunnikova L.P. Synthesis of amines with a tropylildenic fragment with potential antifungal activity. Butlerov Soobshch. 2011. V. 28. N 20. P. 80-83 (in Russian).

11. Yunnikova L.P., Akent'eva T.A. Synthesis of N-arylmethyl-4(1-cyclohepta-2,4,6-trienyl) anilines. Estestv. Tekhnich. Nauki. 2010. N 6 (50). P. $86-90$ (in Russian). 
13. Nair V., Abhilash K.G. [8+2] Cycloaddition reactions in organic synthesis. Synlett. 2008. 03. P. 301-312.

14. Sanechika K., Kajigaeshi S., Kanemasa S. Azafulvenes;51. A Facile Synthesis of 8-Azaheptafulvenes. Synthesis. 1977. N 3. P. 202. DOI:10.1055/s-1977-24325.

15. Юнникова Л.П., Лихарева Ю.Е., Акентьева Т.А Электрофильное тропилирование 2-аминопиридина. Журн. общ. химии. 2017. Т. 87. Вып. 2. С. 333-335.

16. Юнникова Л. П., Акентьева Т.А., Эсенбаева В.В. Тропилирование ариламинов и антимикробная активность 4-(7-циклогепта-1,3,5-триенил)-N-(1-циклогепта-2,4,6триенил)анилина. Хим.-фарм. журн. 2015. Т. 49. № 4. С. 33.

17. Хабриев Р.У. Руководство по экспериментальному (доклиническому) изучению новых фармакологических веществ. М.: Изд-во «Медицина». 2005. С. 515-532.

18. CrysAlisPro. Agilent Technologies. Version 1.171.37.33 (release 27-03-2014 CrysAlis171 .NET).

19. Sheldrick G.M. Crystal structure refinement with SHELXL. Acta Cryst. 2015. C71. P. 3-8.

20. Dolomanov O.V., Bourhis L.J., Gildea R.J, Howard J.A.K., Puschmann H.J. OLEX2: a complete structure solution, refinement and analysis program. Appl. Cryst. 2009. 42. P. 339-341.
12. Fehlinger M., Abraham W. Calix[4]arenes bearing a tropylium substituent as hosts for organic cations. J. Incl. Phenom. Macrocyclic Chem. 2007. V. 58. No. 3-4. P. 263-274.

13. Nair V., Abhilash K.G. [8+2] Cycloaddition reactions in organic synthesis. Synlett. 2008. 03. P. 301-312.

14. Sanechika K., Kajigaeshi S., Kanemasa S. Azafulvenes; 51. A Facile synthesis of 8-Azaheptafulvenes. Synthesis. 1977. N 3. P. 202. DOI:10.1055/s-1977-24325.

15. Yunnikova, L.P., Likhareva, Y.E., Akent'eva, T.A. Electrophilic tropylation of 2-aminopyridine. Russ. J. Gen. Chem. 2017. 87. P. 347. DOI: 10.1134/S1070363217020323.

16. Yunnikova, L.P., Akent'eva, T.A., Ésenbaeva, V.V. Arylamine tropyling and antimicrobial activity of 4- (7-cyclohepta-1,3,5-trienyl) -N- (1-cyclohepta-2,4,6-trienyl) aniline. Chem.-Farm. J. 2015. 49. P. 243. DOI: 10.1007/s11094-0151263-3.

17. Khabriev R.U. Guidance on experimental (preclinical) study of new pharmacological substances. M.: Izd-vo "Meditsina". 2005. P. 515-532 (in Russian).

18. CrysAlisPro. Agilent Technologies. Version 1.171.37.33 (release 27-03-2014 CrysAlis171 .NET).

19. Sheldrick G.M. Crystal structure refinement with SHELXL. Acta Cryst. 2015. C71. P. 3-8.

20. Dolomanov O.V., Bourhis L.J., Gildea R.J, Howard J.A.K., Puschmann H.J. OLEX2: a complete structure solution, refinement and analysis program. Appl. Cryst. 2009. 42. P. 339-341.

Поступила в редакиию 06.02.2018

Принята к опубликованию 10.12.2018

Received 06.02.2018

Accepted 10.12.2018 